Efficient Vol 1 (1) (2018): 77-85 DOI: https://doi.org/10.15294/efficient.vii1.27223 EFFICIENT

Indonesian Journal of Development Economics http: https://journal.unnes.ac.id/sju/index.php/efficient

\title{
Analisis Pendapatan dan Faktor-Faktor yang Mempengaruhi Produksi Usaha Budidaya Tambak Ikan
}

\author{
Ahmad Fahrudin ${ }^{\bowtie}$ \\ Jurusan Ekonomi Pembangunan,Fakultas Ekonomi, Universitas Negeri Semarang \\ Permalink/DOI: https://doi.org/10.15294/efficient.vii1.27223 \\ Received: July 2017; Accepted: October 2017; Published: January 2018
}

\begin{abstract}
This study aims to determine how much influence the use of factors of production to the production of fish farms also the amount of income of farmers. The results of the partial test ( $t$-test) showed that the land variable, labor and feed significantly influence while seeds and pharmaceuticals do not give significant influence on the production of aquaculture fish.Based on the results obtained value of F-test F-count of 573 with significant value 0,000, simultantly production of aquaculture fish influanted by the land, labor, seed, feed and pharmaceuticals $97.8 \%$. Based on the regression analysis results obtained the coefficient value of land, labor, seed, feed and pharmaceuticals influence positively the results of aquaculture fish production. the average income received by each fish farmer in the district Tugu every month is Rp 940 342. Suggestions that can be taken based on the results of these findings is the fish farmers who can not increase the land area, therefore the fish farmers can improve feed or labor's breeding in order to increase production yield, because labor and feed became the dominant variable after land area. In addition Tugu District Government should further contribute to the improvement of the productivity of farmers in terms of skills and technology in way of aquaculture extension, or in terms of capital. And with regard to the existence of pond are pressured by industry and pollution.
\end{abstract}

Keywords: Income, Land Area, Labor, Seed, Feed, Pharmaceuticals And Production Result

\begin{abstract}
Abstrak
Penelitian ini bertujuan untuk mengetahui seberapa besar pengaruh penggunaan faktor produksi terhadap hasil produksi tambak ikan serta besarnya pendapatan petani. Hasil uji secara parsial (uji-t) dalam penelitian menunjukkan bahwa variabel luas lahan, tenaga kerja dan pakan berpengaruh secara signifikan sedangkan bibit dan obat-obatan tidak berpengaruh secara signifikan terhadap hasil produksi tambak ikan; variabel obat-obatan tidak berpengaruh signifikan terhadap hasil produksi. Berdasarkan hasil uji-F diperoleh nilai $F_{\text {hitung }}$ sebesar 573 dengan nilai signifikansi 0,000 secara bersama-sama hasil produksi tambak ikan dipengaruhi oleh luas lahan, tenaga kerja, bibit, pakan dan obat-obatan sebesar 97,8\%. Berdasarkan hasil analisis regresi diperoleh nilai koefisien variabel luas lahan, tenaga kerja, bibit, pakan dan obat-obatan berpengaruh secara positif terhadap hasil produksi tambak ikan. Untuk pendapatan rata-rata yang diterima oleh setiap petani tambak ikan di Kecamatan Tugu setiap bulannya sebesar Rp 940.342 . Saran yang dapat diambil berdasarkan hasil temuan ini adalah para petani tambak yang tidak memungkinkan meningkatkan luas lahannya maka petani dapat meningkatkan pakan atau tenaga kerja dalam perawatan agar hasil produksi meningkat, karena tenaga kerja dan pakan menjadi variabel yang dominan setelah variabel luas lahan. Selain itu Pemerintah Kecamatan Tugu hendaknya lebih ikut berperan dalam peningkatan produktivitas petani dari segi keterampilan maupun teknologi budidaya tambak dengan cara penyuluhan, ataupun dari segi permodalan. Serta memperhatikan keberadaan lahan tambak yang semakin terdesak oleh industri dan pencemaran.
\end{abstract}

Kata Kunci: Pendapatan, Luas Lahan, Tenaga Kerja, Bibit, Pakan, Obat-Obatan dan Hasil Produksi

How to Cite: Fahrudin, A. (2018). Analisis Pendapatan dan Faktor-Faktor yang Mempengaruhi Produksi Usaha Budidaya Tambak Ikan. EFFICIENT Indonesian Journal of Development Economics, 1(1), $77-85$. https://doi.org/10.15294/efficient.vii1.27223

(C) 2018 Universitas Negeri Semarang. All rights reserved

\footnotetext{
Alamat Korespondensi :

Alamat: Gedung L2 Lantai 2 FE Unnes

Kampus Sekaran, Gunungpati, Semarang, 50229

E-mail : jurnalefficient@gmail.com
} 


\section{PENDAHULUAN}

Kota Semarang merupakan salah satu kota di Provinsi Jawa Tengah yang berbatasan langsung dengan laut jawa, sehingga sangat berpotensi untuk dikembangkan produksi perikanannya khususnya budidaya tambak. Kecamatan Tugu menjadi salah satu kecamatan yang terletak pada wilayah utara Kota Semarang, kondisi ini menempatkan kecamatan Tugu berbatasan langsung dengan laut jawa dengan luas wilayah sebesar 3.228,06 Ha yang terbagi dalam tujuh kelurahan dengan jumlah penduduk pada tahun 2013 sebanyak 31.279 jiwa. Jika dilihat dari mata pencaharian penduduk, sebagian besar penduduk bekerja pada sektor jasa yaitu sebesar $44 \%$ dan buruh industri sebesar $21 \%$ sedangkan sektor pertanian dan perikanan sebanyak $14 \%$, sisanya 21\% bekerja pada sektor lainnya (Statistik Daerah Kecamatan Tugu, 20014). Meskipun di Kecamatan Tugu terdapat kawasan industri yang cukup besar dan banyak memberikan lapangan pekerjaan bagi para penduduk sekitar maupun luar daerah, namun di Kecamatan Tugu juga menjadi sentra rumah tangga usaha budidaya tambak ikan terbesar di Kota Semarang.

Meskipun Kecamatan Tugu merupakan penghasil produksi perikanan tambak terbesar di Kota Semarang dibandingkan dengan kecamatan-kecamatan yang lain, namun untuk hasil produksinya dari tahun ke tahun tidak setabil atau mengalami kenaikan dan penurunan.

Tinggi rendahnya tingkat produksi sangat dipengaruhi oleh faktor-faktor produksi, begitu juga produksi budidaya perikanan tambak di Kecamatan Tugu Kota Semarang dipengaruhi oleh faktor-faktor produksi budidaya tambak, dalam hal ini antara lain : luas lahan, bibit, pakan, obat-obatan dan tenaga kerja.

Tambak merupakan pertanian basah tetapi biasanya di pakai untuk memelihara berbagai ikan seperti ikan bandeng, udang, ikan nila atau ikan mujair (Tati Nur, 2012). Sedangkan menurut Sri Rusmiyanti dalam bukunya Pintar Budidaya Udang Windu Tambak merupakan kolam yang di bangun untuk membudidayakan ikan, udang dan hewan air lainya yang hidup di air (Sri Rusmiyati, 2012). Jadi dapat disimpulkan tentang arti dari Petani tambak adalah petani udang, ikan atau sejenis hewan air, yang dimana orang tersebut memperoleh mata pencaharian pokok dengan melakukan kegiatan di bidang produksi dan budidaya ikan di tambak.

Dalam kegiatan produksi, erat kaitannya dengan teori produksi. Banyak jenis aktifitas yang terjadi didalam proses produksi, yang meliputi perubahan-perubahan bentuk, tempat, dan waktu penggunaan hasil-hasil produksi. Masingmasing perubahan ini menyangkut penggunaan input untuk menghasikan output yang diinginkan. Jadi produksi meliputi semua aktifitas menciptakan barang dan jasa (Ari Sudarman, 1999). Tujuan dari kegiatan produksi adalah memaksimalkan jumlah output dengan sejumlah input tertentu. Fungsi produksi dinyatakan dalam persamaan berikut $Q=f(K, L . .$. $\mathrm{Q}$ adalah produksi dan K,L adalah input dari faktor produksi meliputi K (Kapital) atau modal yang digunakan dalam produksi dan L (Labour) atau tenaga kerja yang digunakan dalam produksi. Fungsi produksi menunjukan bahwa jumlah hasil produksi sangat tergantung pada faktor produksi. Asumsi dasar mengenai hubungan antara produksi dengan faktor-faktor produksi terdapat pada teori ekonomi.

Dalam fungsi produksi terdapat hukum The Law of Deminishing Return yaitu bila satu macam input ditambah penggunaannya sedang input-input lain tetap maka tambahan output yang dihasilkan dari setiap tambahan satu unit input yang ditambahkan, mula-mula menaik 
tetapi kemudian seterusnya menurun bila input tersebut terus ditambah.

Faktor produksi disebut juga korbanan produksi, karena faktor produksi tersebut dikorbankan untuk mendapatkan hasil produksi. Macam-macam faktor produksi atau input ini berikut jumlah dan kualitasnya perlu diketahui oleh seorang produsen. Oleh karena itu, untuk menghasilkan suatu produk, maka diperlukan pengetahuan hubungan antara faktor produksi (input) dan hasil produksi (output) (Soekartawi, 2003).

Luas lahan, menurut Mubyarto (1989), lahan sebagai salah satu faktor produksi yang merupakan pabriknya hasil-hasil pertanian yang mempunyai kontribusi yang cukup besar terhadap usaha tani tambak. Besar kecilnya produksi dari usaha tani antara lain dipengaruhi oleh luasnya lahan yang digunakan.

Tenaga kerja, menjadi salah satu faktor produksi yang memegang peran penting dalam kegiatan usaha tani tambak. Menurut Vink, G.J. (1994), tenaga kerja dapat berarti sebagai hasil jerih payah yang dilakukan oleh seseorang, pengaruh tenaga untuk mencapai suatu tujuan kebutuhan tenaga kerja dalam pertanian sangat tergantung pada jenis pertanian yang diusahakan.

Bibit/benih pada umumnya bibit ikan yang digunakan oleh para petani budidaya tambak di Kecamatan Tugu menggunakan benih gelondongan dari pantai benih bukan berupa nener, karena penggunaan bibit gelondongan lebih kebal terhadap hama disekitar seperti burung. Pemilihan bibit yang baik dan banyaknya penebaran benih setiap kolamnya akan mempengaruhi pada tingkat produksi yang dihasilkan.
Pakan, pakan adalah unsur yang paling penting dalam usaha budidaya tambak dengan maksud agar ikan atau udang tumbuh dan berkembang menjadi lebih besar. Tingkat produktifitas usaha tani tambak pada dasarnya sangat dipengaruhi oleh tingkat penerapan teknologinya, dan salah satu diantaranya adalah pemberian pakan. Dengan teknik penggunaan pakan yang baik maka produtivitas ikan akan meningkat (Budiono, 2002).

Obat-obatan, hama dan penyakit merupakan kendala bagi upaya peningkatan produksi suatu produk pertanian. Kerugian dan penyakit yang disebabkan oleh serangan hama dan penyakit ikan sangat besar. Oleh karena itu, usaha dan pengendalian hama dan penyakit ikan saat ini merupakan suatu keharusan yang dilakukan untuk mencapai produksi ikan yang diinginkan (Rizal, 2010).

Untuk hasil produksi (output) dari kegiatan budidaya tambak, akan berpengaruh pada tingkat pendapatan petani. Purwantiningdyah D.N (2003) menyatakan, bahwa pendapatan petani dapat diperhitungkan dari total penerimaan yang berasal dari nilai penjualan hasil produksi dikurangi dengan total nilai pengeluaran. Bagi petambak, ikan yang dihasilkan dikali dengan harga penjualan dikurangi biaya-biaya (pengeluran) untuk proses produksi. Total pendapatan diperoleh dari total penerimaan dikurangi dengan total biaya dalam suatu proses produksi. Adapun total penerimaan diperoleh dari produksi fisik dikalikan dengan harga produk.

\section{METODE PENELITIAN}

Analisis data yang digunakan dalam penelitian ini adalah sebagai berikut; 


\section{Analisis Regresi Linier Berganda}

Analisis regresi digunakan untuk mengetahui pengaruh luas lahan, tenaga kerja, jumlah pakan, jumlah obat-obatan dan bibit terhadap jumlah produksi ikan di Kecamatan tugu semarang kota yang dinyatakan dalam bentuk fungsi sebagai berikut:

$\mathrm{Y}=\mathrm{f}\left(\mathrm{X}_{1}, \mathrm{X}_{2}, \mathrm{X}_{3}, \ldots \ldots \mathrm{X}_{\mathrm{n}}\right)$

Feldstein (1988) mengadakan transformasi ke bentuk linear dengan menggunakan logaritma natural (ln) guna menghitung nilai elastisitas dari masing-masing variabel bebas terhadap variabel terikat ke dalam model sehingga diperoleh persamaan:

$\operatorname{Ln} Y=\operatorname{Ln} \beta_{0}+\beta_{1} \operatorname{Ln} X_{1}+\beta_{2} \operatorname{Ln} X_{2}+\beta_{3} \operatorname{Ln} X_{3}+\mu$

Tingkat signifikansi dari masing-masing koefisien regresi variabel independen terhadap variabel dependen maka dapat menggunakan uji statistik diantaranya :

\section{Pengujian Hipotesis}

\section{Uji Parsial (Uji t)}

Uji-t statistik ini dilakukan dengan membandingkan $\mathrm{t}$ hitung. Nilai t tabel dapat dilihat pada tabel statistic pada tingkat signifikansi (o,05) dengan derajat kebebasan (df) sebesar (n-k-1), dimana n adalah jumlah sampel, dan $\mathrm{k}$ adalah jumlah variabel independen.

\section{Uji Bersama-sama ( Uji F )}

Uji signifikansi ini pada dasarnya dimaksudkan untuk membuktikan secara statistik bahwa seluruh variabel independen terhadap variabel dependen berpengaruh secara signifikan. Kriteria pengujiannya apabila nilai Fhitung < F-tabel maka hipotesis diterima yang artinya seluruh variabel independen yang digunakan tidak berpengaruh secara signifikan terhadap variabel dependen.apabila F-hitung > Ftabel maka hipotesis ditolak yang berarti seluruh variabel independen berpengaruh secara signifikan terhadap variabel dependen dengan tarif signifikan tertentu.

\section{Analsis Koefisien Determinasi $\left(\mathbf{R}^{2}\right)$}

Analisis koefisien determinasi digunakan untuk mengetahui besarnya pengaruh variabel independen terhadap variabel dependen. Koefisien determinasi $\left(\mathrm{R}^{2}\right)$ yang kecil atau mendekati nol berarti kemampuan variabelvariabel independen dalam menjelaskan variasi variabel dependen sangat terbatas. Nilai $\mathrm{R}^{2}$ yang mendekati satu berarti variabel-variabel independen memberikan hampir semua informasi yang dibutuhkan untuk memprediksi variabel-variabel dependen.

\section{Uji Asumsi Klasik}

\section{Uji Normalitas}

Uji normaliats bertujuan untuk menguji apakah model regresi, variabel terikat dan variabel bebas keduanya mempunyai distribusi normal atau tidak. Model regresi yang baik adalah memiliki distribusi data normal atau mendekati normal (Shocrul, 2011).

\section{Uji Multikolinearitas}

Uji Multikolinearitas bertujuan untuk menguji apakah model regresi ditemukan adanya korelasi antar variabel bebas (Shocrul, 2011). Model regresi yang baik seharusnya tidak terdapat korelasi antara variabel bebas.

\section{Uji Heteroskedastisitas}

Asumsi penting dalam regresi linier klasik adalah bahwa gangguan yang muncul dalam regresi populasi adalah homoskedastik, yaitu semua gangguan memiliki varians yang sama. Kasus heteroskedastisitas terjadi apabila variabel 
gangguan tidak mempunyai varians yang sama untuk semua observasi.

\section{Analisis Pendapatan}

Analisis pendapatan dalam usaha budidaya tambak ikan digunakan persamaan sebagai berikut :

$\pi=\mathbf{T R}-\mathbf{T C}$

Dimana:

$\pi$ = Pendapatan (Rp)

$\mathrm{TR}=$ Total Revenue (Total penerimaan) $(\mathrm{Rp})$

$\mathrm{TC}=$ Total Cost (Total Biaya) (Rp)

Pendapatan adalah hasil yang diperoleh dari pembudidaya tambak ikan (besarnya hasil produksi ikan dikalikan dengan harga jual) setelah dikurangi dengan total biaya pengeluaran dalam budidaya tambak ikan selama satu kali proses budidaya. Total penerimaan (Total Revenue/TR) adalah total jumlah hasil yang diperoleh dalam kegiatan usaha budidaya tambak ikan dikalikan dengan harga jual ikan. Total biaya (Total Cost) adalah total jumlah dari biaya tetap (Fixed Cost/FC) dengan biaya variabel (Variable Cost/VC) dalam kegiatan usaha budidaya tambak ikan.

\section{HASIL DAN PEMBAHASAN}

\section{Analisis Regresi Liniear Berganda}

Tabel 1. Hasil Analisis Regresi Linier Berganda

Coefficients $^{\mathrm{a}}$

\begin{tabular}{|c|c|c|c|c|c|c|}
\hline \multirow{2}{*}{\multicolumn{2}{|c|}{ Model }} & \multicolumn{2}{|c|}{$\begin{array}{l}\text { Unstandardized } \\
\text { Coeff icients }\end{array}$} & \multirow{2}{*}{$\begin{array}{c}\text { Standardized } \\
\text { Coefficients } \\
\text { Beta }\end{array}$} & \multirow[b]{2}{*}{$t$} & \multirow[b]{2}{*}{ Sig. } \\
\hline & & $\mathrm{B}$ & Std. Error & & & \\
\hline \multirow[t]{6}{*}{1} & (Constant) & 156.402 & 31.406 & & 4.980 & .000 \\
\hline & Luas Lahan (Hektar) & 199.909 & 23.650 & .657 & 8.453 & .000 \\
\hline & $\begin{array}{l}\text { Jmlh Tenaga Kerja } \\
\text { (Orang) }\end{array}$ & 69.328 & 17.599 & .211 & 3.939 & .000 \\
\hline & Jumlah Bibit (Ekor) & .005 & .003 & .087 & 1.737 & .087 \\
\hline & Jumlah Pakan (kg) & .057 & .017 & .096 & 3.465 & .001 \\
\hline & Jumlah Obat (kg) & .176 & .651 & .015 & .271 & .788 \\
\hline
\end{tabular}

a. Dependent Variable: Hasil Produksi Ikan (kg)

Sumber : Data Primer diolah, 2016

Berdasarkan tabel 4.8 dapat diperoleh persamaan regresi sebagai berikut :

$Y=156,402+199,909 X 1+69,328 X 2+0,005$ $\mathrm{X} 3+0,057 \mathrm{X} 4+0,176 \mathrm{X} 5 \mathrm{e}$

Dari tabel menunjukkan bahwa nilai koefisie variabel luas lahan, tenaga kerja, bibit, pakan dan obat-obatan berpengaruh positif terhadap hasil produksi usaha budidaya tambak ikan.

\section{Uji Asumsi Klasik}

Uji normalitas data dapat diketahui bahwa titik-titik pada gambar grafik Normal P-P Plot berhimpit sangat dekat dan cenderung membentuk garis diagonal, sehingga dapat disimpulkan bahwa model regresi terdistribusi normal. Uji normalitas dapat dilihat pada grafik Normal P-P Plot sebagai berikut : 


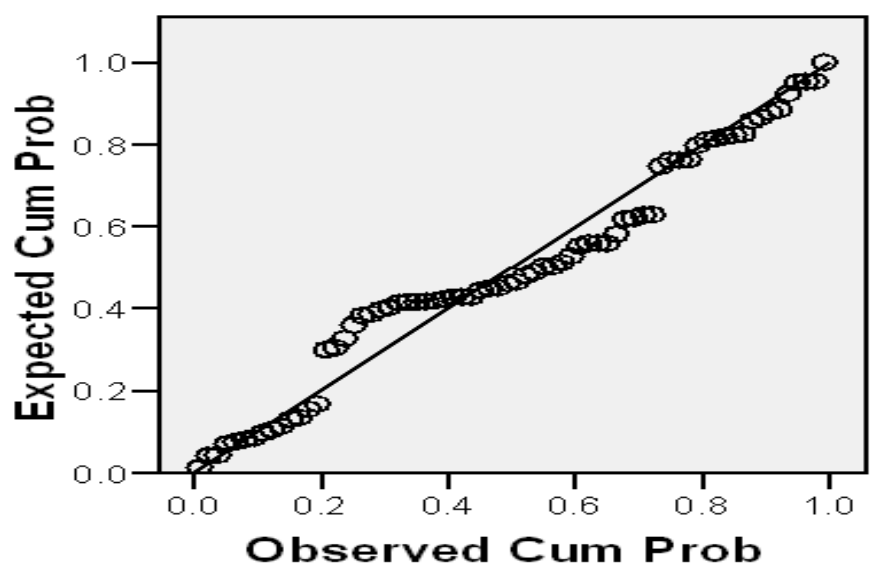

Gambar 1. Hasil Produksi Tambak Ikan

Hasil perhitungan multikolinearitas menggunakan SPSS adalah sebagai berikut :

Tabel 2. Hasil Uji Multikolinearitas Data

Coefficients $^{\mathrm{a}}$

\begin{tabular}{|c|c|c|c|c|c|c|}
\hline \multirow[b]{2}{*}{ Mode } & & \multicolumn{3}{|c|}{ Correlations } & \multicolumn{2}{|c|}{ Collinearity Statistics } \\
\hline & & Zero-order & Partial & Part & Tolerance & VIF \\
\hline \multirow[t]{5}{*}{1} & $\begin{array}{l}\text { Luas Lahan (Hektar) } \\
\text { Jumlah Tenaga Kerja }\end{array}$ & .913 & .286 & .156 & .126 & 7.707 \\
\hline & (Orang) & .940 & .442 & .073 & .119 & 8.423 \\
\hline & Jumlah Bibit (Ekor) & .905 & .212 & .032 & .136 & 7.335 \\
\hline & Jumlah Pakan (kg) & .479 & .397 & .064 & .446 & 2.240 \\
\hline & Jumlah Obat (kg) & .899 & .034 & .005 & .106 & 9.413 \\
\hline
\end{tabular}

a. Dependent Variable: Hasil Produksi lkan (kg)

Sumber : data primer diolah, 2016

Berdasarkan Tabel menunjukkan setiap regresi ini terbebas dari masalah variabel bebas dalam penelitian ini mempunyai nilai tolerance lebih besar dari 0,1 dan nilai VIF multikolonearitas. Salah satu uji untuk kurang dari 10. Sehingga dapat melihat penyebaran dari varians residual disimpulkanbahwa variabel bebas dalam model (Santoso, 2005). 


\section{Scatterplot}

\section{Dependent Variable: Hasil Produksi lkan (kg)}

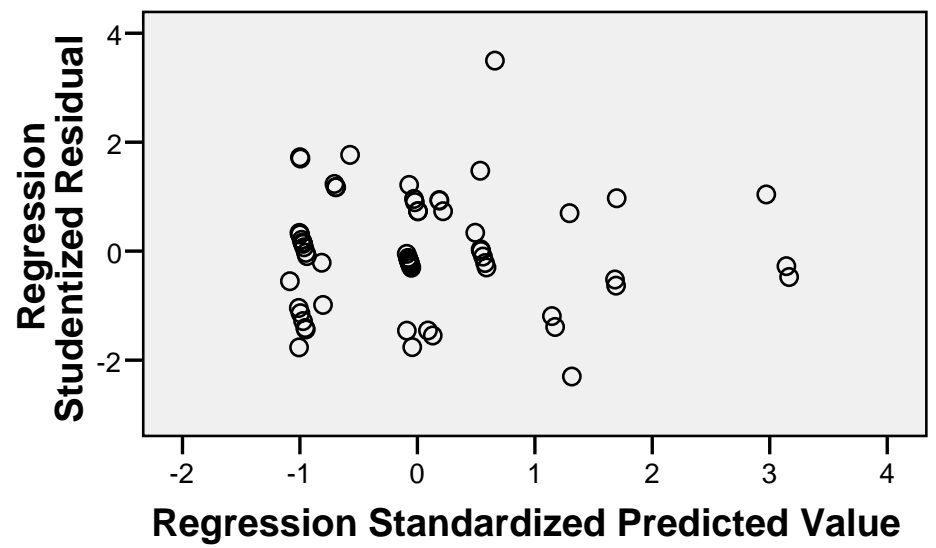

Gambar 2. Grafik Scatterplot

Gambar diatas menunjukkan grafik dibawah angka nol pada sumbu Y. Hal ini dapat scatterplot terlihat bahwa titik-titik menyebar secara acak dan tidak membentuk suatu pola tertentu, serta menyebar baik diatas maupun disimpulkan bahwa model regresi linier berganda pada penelitian ini tidak terjadi heteroskedastisitas.

\section{Uji Hipotesis}

Tabel 3. Uji Koefisien Determinasi $\left(\mathrm{R}^{2}\right)$

Model Summary

\begin{tabular}{|r|r|r|l|l|}
\hline Model & R & R Square & $\begin{array}{l}\text { Adjusted } \\
\text { Square }\end{array}$ & $\begin{array}{l}\text { R Std. Error of the } \\
\text { Estimate }\end{array}$ \\
\hline 1 & .990 & .979 & .978 & 70.31680 \\
\hline
\end{tabular}

Predictors: (Constant), Luas lahan, Tenaga kerja, Ln Bibit, Pakan, Obat

Sumber : data primer diolah 2016

Berdasarkan tabel 4.13 diperoleh koefisien determinasi ( $\mathrm{R}$ square) sebesar 0,978, hal ini menunjukan bahwa variabel luas lahan, tenaga kerja, bibit, pakan dan obat-obatan dapat menerangkan $97,9 \%$ terhadap Produksi budidaya tambak ikan di Kecamatan Tugu Kota Semarang, sedangkan sisanya $2,1 \%$ dapat dijelaskan oleh variabel lain yang tidak dimasukan dalam model analisis dalam penelitian ini. 
Tabel 4. Hasil Uji t dengan Variabel Dependen Hasil Produksi Budidaya Tambak Ikan

Coefficients

\begin{tabular}{|c|c|c|c|c|c|c|}
\hline \multirow[b]{2}{*}{$\mathrm{Mod}$} & & \multicolumn{2}{|c|}{$\begin{array}{l}\text { Unstandardized } \\
\text { Coeff icients }\end{array}$} & \multirow{2}{*}{$\begin{array}{c}\text { Standardized } \\
\text { Coeff icients } \\
\text { Beta }\end{array}$} & \multirow[b]{2}{*}{$\mathrm{t}$} & \multirow[b]{2}{*}{ Sig. } \\
\hline & & $\mathrm{B}$ & Std. Error & & & \\
\hline \multirow[t]{6}{*}{1} & (Constant) & 156.402 & 31.406 & & 4.980 & .000 \\
\hline & Luas Lahan (Hektar) & 199.909 & 23.650 & .657 & 8.453 & .000 \\
\hline & $\begin{array}{l}\text { Jmlh Tenaga Kerja } \\
\text { (Orang) }\end{array}$ & 69.328 & 17.599 & .211 & 3.939 & .000 \\
\hline & Jumlah Bibit (Ekor) & .005 & .003 & .087 & 1.737 & .087 \\
\hline & Jumlah Pakan (kg) & .057 & .017 & .096 & 3.465 & .001 \\
\hline & Jumlah Obat (kg) & .176 & .651 & .015 & .271 & .788 \\
\hline
\end{tabular}

a. Dependent Variable: Hasil Produksi Ikan (kg)

Sumber : data primer diolah, 2016

Berdasarkan Tabel diatas, Hasil Uji t berpengaruh secara signifikan terhadap hasil menunjukkan bahwa variabel luas lahan, tenaga produksi tambak ikan di Kecamatan Tugu kota kerja dan pakan berpengaruh secara signifikan Semarang. sedangkan variabel bibit dan obat-obatan tidak

Tabel 5. Hasil Uji F dengan Variabel dependent Hasil Produksi

Budidaya Tambak

ANOVA

\begin{tabular}{|c|c|c|c|c|c|c|}
\hline Model & & $\begin{array}{l}\text { Sum of } \\
\text { Squares }\end{array}$ & $\mathrm{df}$ & Mean Square & $F$ & Sig. \\
\hline \multirow[t]{3}{*}{1} & Regression & 15091710 & 5 & 3018342.038 & 573.209 & $.000^{a}$ \\
\hline & Residual & 337004.1 & 64 & 5265.689 & & \\
\hline & Total & 15428714 & 69 & & & \\
\hline
\end{tabular}

a. Predictors: (Constant), Jumlah Obat (kg), Jumlah Pakan (kg), Jumlah Bibit (Ekor), Jmlh Tenaga Kerja (Orang), Luas Lahan (Hektar)

b. Dependent Variable: Hasil Produksi Ikan (kg)

Sumber : data primer diolah, 2016

Tabel diatas menunjukan bahwa nilai Fhitung yang diperoleh adalah 573,209 dan nilai signifikansi sebesar o,ooo, karena nilai probabilitas signifikansi lebih kecil dari 0,05 maka dapat disimpulkan bahwa variabel luas lahan, tenaga kerja, bibit, pakan dan obat-obatan secara bersama-sama berpengaruh positif terhadap hasil produksi budidaya tambak ikan di Kecamatan Tugu Kota Semarang.

\section{Analisis Pendapatan}

Biaya total (TC) rata-rata yang dikeluarkan oleh setiap petani dalam satu kali periode produksi sebesar Rp 10.301.143,

sedangkan rata-rata penerimaan (TR) dari hasil produksi ikan sebanyak $1.046 \mathrm{~kg}$ dikalikan dengan harga jual ikan rata-rata Rp 14.386 per kilogram ditemukan hasil sebesar Rp 15.002.857, jadi pendapatan yang diterima oleh petani setiap 
kali musim panen tambak ikan adalah TR-TC (Rp 15.002.857 - Rp 10.301.143 = Rp 4.701.714) sehingga diperoleh pendapatan rata-rata setiap petani tambak dalam satu kali produksi sebesar $\mathrm{Rp}$ 4.701.714,.

\section{SIMPULAN}

Secara parsial, variabel luas lahan, tenaga kerja dan pakan berpengaruh signifikan terhadap variabel dependen yaitu hasil produksi budidaya tambak ikan di Kecamatan Tugu Kota Semarang. Variabel luas lahan, tenaga kerja, bibit/benih, pakan dan obat-obatan secara bersama-sama berpengaruh dan signifikan terhadap hasil produksi tambak ikan di Kecamatan Tugu. Variabel yang paling dominan mempengaruhi hasil produksi budidaya tambak ikan di kecamatan Tugu Kota Semarang yaitu variabel luas lahan. Pendapatan rata-rata selama satu kali musim produksi yang diperoleh setiap petani budidaya tambak ikan di Kecamatan Tugu Kota Semarang sebesar Rp 4.701.714 per 2,3 Ha. Saran yang dapat dijadikan referensi dalam upaya meningkatkan produktivitas dalam budidaya ikan tambak yaitu petani tambak lebih meningkatkan pengetahuanya tentang peningkatan produksi ikan dengan sistem intensifikasi. Berdasarkan hasil penelitian, tenaga kerja dan pakan menjadi variabel yang dominan setelah variabel luas lahan. Oleh karena itu bagi para petani tambak yang tidak memungkinkan meningkatkan luas lahannya maka petani dapat meningkatkan pakan atau tenaga kerja dalam perawatan agar memperoleh hasil produksi yang lebih tinggi.

\section{DAFTAR PUSTAKA}

Ajija, Shocrul. 2011. Cara Cerdas Menguasai EViews. Jakarta. Salemba Empat.

BPS Kota Semarang. 2014. Statistik Daerah Kecamatan Tugu. Kota Semarang.

Budiono, 2002. Ekonomi Mikro Seri Sinopsis: Pengantar Ilmu Ekonomi No.1. BPFE, Yogyakarta.

Gujarati, D.N. 2012. Dasar-dasar Ekonometrika, Terjemahan Mangunsong, R.C., Salemba Empat, Buku 2, Edisi 5, Jakarta.

Mala, Tati Nur dkk. 2012. Pengantar Ilmu Pertanian, Yogyakarta: Graha Ilmu.

Mubyarto. 1989. Pengantar Ekonomi Pertanian. Lembaga Pendidikan dan Penerangan Ekonomidan Sosial. Jakarta: PT. Gramedia Pustaka Utama.

Purwantiningdyah, D.N., 2003. Dalam Muhamad Yasin, 2013 "Analisis Ekonomi Usaha Tambak Udang Berdasarkan Luas Lahan di Kabupaten Parigi Moutong Provinsi Sulawesi Tengah”, FE Universitas Al-Khairaat, Palu.

Rizal, 2010. Faktor-faktor yang Berpengaruh terhadap Proses Pelaksanaan Program Sekolah Lapangan Pengendalian Hama Terpadu (SLPHT) Padi di Kabupaten Jember. Politeknik Negeri Jember.

Rusmiyati, Sri. 2012. Pintar Budidaya Udang Windu. Jogjakarta : Baru Press.

Setiawan, A., \& Prajanti, S. 2015. Analisis Efisiensi Penggunaan Faktor-Faktor Produksi Usaha Tani Jagung di Kabupaten Grobogan Tahun 2008. JEJAK: Jurnal Ekonomi Dan Kebijakan, 4(1). doi:http://dx.doi.org/10.15294/jejak.v4i1.4642

Soekartawi, 2003. Teori Ekonomi Produksi dengan Pokok Bahasan Analisi Fungsi Cobb-Douglas, PT. Raja Grafindo Persada, Jakarta.

Sudarman, Ari. 1999. Teori Mikro Jilid I. Yogyakarta : BPFE.

Vink, G.J. 1994. Dasar-Dasar Uasaha Tani di Indonesia. PT. Midas Surya Grafindo, Jakarta. 